\title{
Influence of Tropical Climate Conditions on the Quality of Antihypertensive Drugs from Rwandan Pharmacies
}

\author{
Marc Twagirumukiza, An Cosijns, Eveline Pringels, Jean Paul Remon, Chris Vervaet, and Luc Van Bortel* \\ Department of Internal Medicine, University Hospital, Kigali, Rwanda; Laboratory of Pharmaceutical Technology, Faculty of \\ Pharmaceutical Sciences, Ghent University, Ghent, Belgium; Heymans Institute of Pharmacology, Ghent University, Ghent, Belgium
}

\begin{abstract}
The objective of this study was to assess the quality of antihypertensive drugs and to investigate the influence of tropical storage conditions. Drug content and in vitro dissolution tests were performed on 10 test formulations (from Rwanda) and 6 reference formulations (from Belgium or France) after purchase and after 6-month storage under long-term $\left(25 \pm 2{ }^{\circ} \mathrm{C}\right.$ and $60 \pm 5 \%$ relative humidity [RH] $)$ and accelerated $\left(40 \pm 2^{\circ} \mathrm{C}\right.$ and $\left.75 \pm 5 \% \mathrm{RH}\right)$ testing conditions. Twenty percent of test formulations were of substandard content at the time of purchase. After 6 months at accelerated testing conditions, 7 of 10 test formulations were substandard in content and 8 were substandard for the combined criteria of drug content and dissolution, whereas no reference drug became substandard. This study shows that, apart from some drugs being already substandard from purchase, accelerated testing conditions (simulating tropical climate) have deleterious effects on the majority of antihypertensive drug formulations found in the Rwandan market.
\end{abstract}

\section{INTRODUCTION}

Good-quality medicines are a prerequisite to successful treatment. Medicines can be substandard in quantity of active ingredient or in quality from purchase or become substandard because of some degradation. ${ }^{1}$ Poor stability may lead to drugs becoming toxic or increasingly inactive. ${ }^{2}$ High temperature and relative humidity $(\mathrm{RH})$ are the most important factors involved in drug degradation. ${ }^{3}$ Although stability testing at high $\mathrm{RH}$ and temperature is mandatory in the drug development process, ${ }^{2,4}$ this should not exclude quality monitoring of medicines. However, in most of sub-Saharan African (SSA) countries, no systematic quality control is done at entrance to track substandards. ${ }^{5}$

The substandard quality of medicines in developing countries has been largely reported. ${ }^{6-9}$ However, the majority of these reports focus on medicines used in infectious diseases, ${ }^{10-13}$ which are commonly endemic in developing countries. Medicines used in non-communicable disease (NCDs) such as hypertension and other cardiovascular diseases (CVDs) have been poorly addressed. NCDs, specifically CVDs and hypertension, are rarely on the health planning agenda in SSA, ${ }^{14}$ even if they are known now as real public health problems in SSA. ${ }^{15}$ Projections show that, in a few years, CVD will dominate the worldwide fatal illness, ${ }^{16}$ which implies that more emphasis should be put on both risk factors to prevent the trend ${ }^{17}$ and the treatment to reduce mortality. Hypertension is an important risk factor for CVD. The burden of hypertension was estimated at 79.8 million in SSA in $2002 .{ }^{18}$ As for other conditions, in hypertension, the use of substandard quality drugs may result in treatment failure, ${ }^{9}$ including fatal consequences because of low drug content and toxic degradation products. ${ }^{19}$

Rwanda and many sub-Saharan countries ${ }^{2,20,21}$ import the majority of their drugs from various countries. The lack of systematic quality control and a liberalized drug distribution system create an environment favorable for introducing lowquality drugs. In addition, the tropical climate conditions (high temperature and humidity) may alter the quality of drugs

*Address correspondence to Luc Van Bortel, Heymans Institute of Pharmacology, Ghent University, De Pintelaan 185, Block B, 1st Floor, Ghent 9000, Belgium. E-mail: Luc.VanBortel@UGent.be during distribution and storage. This study aimed to assess the quality of antihypertensive drugs from Rwandan pharmacies and to investigate the influence of tropical storage conditions on drug quality.

\section{MATERIALS AND METHODS}

A selection of the most commonly used antihypertensive drugs in Rwanda was listed. In total, 10 different formulations of these drugs were found in 38 pharmacies. Pharmacies included all 4 public pharmacies (located in Kigali or Butare) and 34 randomly selected official private pharmacies in Kigali. A sample of each test formulation with remaining shelf life of at least 2 years was bought and kept in their original package until analysis. Table 1 shows details of all formulations sampled. For each drug, the original brand purchased from a pharmacy in Belgium or France was used as reference. Before analysis, all reference and test formulations were coded to blind the investigator to the origin of the drug during the analysis.

Drug quality was studied by analyzing drug content and in vitro dissolution. A substandard in vitro dissolution profile may indicate decreased bioavailability. ${ }^{22,23}$ The drug content and in vitro dissolution of all formulations were evaluated immediately after purchase and after 6-month storage. Drug storage was done according to the "International Conference on Harmonization ( $\mathrm{ICH}$ ) harmonized tripartite guidelines on Stability testing of new drug substances and products" 24,25 at long-term $\left(25 \pm 2^{\circ} \mathrm{C}\right.$ and $\left.60 \pm 5 \% \mathrm{RH}\right)$ and accelerated testing conditions $\left(40 \pm 2{ }^{\circ} \mathrm{C}\right.$ and $\left.75 \pm 5 \% \mathrm{RH}\right)$, representing storage under Zone II and very hot/humid tropical (Zone IV) conditions, ${ }^{25}$ respectively. All drugs were analyzed using methods specified in the 2006 US Pharmacopeia and National Formulary (USP29-NF24) monograph of the respective drugs. ${ }^{26}$ The assays were repeated three times, and results are the mean of three determinations.

For drug content, the USP29-NF24 ${ }^{26}$ acceptance limits are $90-110 \%$ of the label claim, whereas for in vitro dissolution, the limits of released amount of drug after a recommended period varies from one drug to another ${ }^{26}$ as shown in Table 3.

The difference in dissolution characteristics between reference and test formulations and between test formulations at purchase and after 6 months of storage were compared 
TABLE 1

Formulation samples analyzed of five antihypertensive drugs

\begin{tabular}{|c|c|c|c|c|c|c|}
\hline Drug & Dose (mg) & Packaging & Batch number & Manufacturer & Origin & Type of Rwandan pharmacy \\
\hline \multicolumn{7}{|l|}{ Atenolol } \\
\hline Tenormin* & 100 & Blister & $06 \mathrm{I} 01$ & AstraZeneca & Belgium & NA \\
\hline Betanorm & 100 & Plastic bottles & 71183 & L\&A & Kenya & Public \\
\hline Catenol & 100 & Blister & MD 3583 & Zydus Cadila & India & Private \\
\hline \multicolumn{7}{|l|}{ Captopril } \\
\hline Capoten* & 25 & Blister & A132 & BMS & Belgium & NA \\
\hline Capoten* & 50 & Blister & A176 & BMS & Belgium & NA \\
\hline Captopril Denk & 25 & Blister & 13587 & Denk Pharma & Germany & Public \\
\hline Cetopril & 25 & Blister & KD-358/T25005 & SPP & India & Private \\
\hline Cetopril & 50 & Blister & KD-358/T25105 & SPP & India & Private \\
\hline \multicolumn{7}{|c|}{ Hydrochlorothiazide (HCTZ) } \\
\hline Esidrex* & 25 & Blister & B5133 & Novartis & France & NA \\
\hline HCTZ L\&A & 50 & Plastic bottles & 41155 & L\&A & Kenva & Private \\
\hline HCTZ Cipla & 50 & Plastic bottles & AST05008 & Cipla & India & Public \\
\hline \multicolumn{7}{|l|}{ Methyldopa } \\
\hline Aldomet Belgium* & 250 & Blister & NE53510 & MSD & Belgium & NA \\
\hline Methyldopa L\&A & 250 & Plastic bottles & 45195 & L\&A & Kenya & Private \\
\hline Aldomet Pakistan & 250 & Plastic bottles & H 101 & MSD Pakistan & Pakistan & Public \\
\hline \multicolumn{7}{|l|}{ Propranolol } \\
\hline Inderal* & 40 & Blister & 06K01 & AstraZeneca & Belgium & NA \\
\hline Cepanolol & 40 & Blister & T 24905 & SPP & India & Public \\
\hline
\end{tabular}

using the $f_{2}$ similarity factor. ${ }^{27,28}$ Two dissolution profiles are considered pharmaceutically equivalent if the similarity factor is $\geq 50 .^{29}$ The similarity factor is a logarithmic reciprocal square root transformation of the sum of squared errors and is a measurement of the similarity between the two drug release curves. The $f_{2}$ is given by the following formula ${ }^{29}$ :

$$
f_{2}=50 \times \log \left\{\left[1+\frac{1}{n} \sum_{t=1}^{t=n}\left(R_{t}-T_{t}\right)^{2}\right]^{-0.5} \times 100\right\}
$$

where $n$ stands for the number of time points and $t$ is the time point considered. $R$ equals the reference drug and $T$ is the drug to be tested.

Drug content was determined using high-pressure liquid chromatography (HPLC). The HPLC analyses were carried out using LaChrom equipment (Merck-Hitachi, Darmstadt, Germany). All drug standards were obtained from Sigma Aldrich (Steinheim, Germany). All reagents used during drug assay were of HPLC grade; the other reagents were of analytical grade. ${ }^{26}$ For dissolution testing, a VanKel VK 7010 dissolution apparatus linked to a VK 8000 automatic sampler (VanKel Technology, Cary, NC) was used. A Lambda 12 UV/ VIS spectrophotometer (Perkin Elmer, Norwalk, CT) was used to determine the drug concentration in the dissolution media.

\section{RESULTS}

Except for two formulations of captopril (counting for $20 \%$ of test formulations), all antihypertensive formulations were within standards at purchase time in terms of content and in vitro dissolution profiles. Although within standards, several formulations were already near the lower content acceptance limit at purchase. The two substandard captopril formulations Cetopril $25 \mathrm{mg}$ and Cetopril $50 \mathrm{mg}$ contained 38.6 (154.5\%) and $26.5 \mathrm{mg}(53.0 \%)$, respectively.
After 6-month storage at ambient conditions, the content of the two Cetopril formulations remained (as expected) substandard. In addition, the content of the methyldopa formulation from Kenya also became substandard. This formulation was already close to the lower acceptance limit at purchase time (Table 2). On average, the content of test drug formulations decreased $1.7 \pm 1.1 \%$ after 6 months of storage. The largest decrease $(3.3 \%$ ) was found for the atenolol (Catenol) from India, followed by hydrochlorothiazide (HCTZ) L\&A from Kenya (3.0\%), propranolol (Cepanolol; 2.4\%) from India, methyldopa (Aldomet) from Pakistan $(2.2 \%)$, and captopril $50 \mathrm{mg}$ (Cetopril, 2.1\%) from India. The smallest decrease $(0.2 \%)$ was found for HCTZ Cipla from India.

After 6-month storage at long-term testing conditions, the dissolution profiles were within the limits of good quality in all test and reference drugs (Table 3). However, the formulation of atenolol (Catenol) and propranolol (Cepanolol) showed a decreased drug dissolution profile compared with their dissolution profiles at purchase (Table 4). At 6 months under long-term testing conditions, 6 of 10 test formulations (60\%) showed a lower dissolution profile than their reference drug formulation.

After 6-month storage at accelerated testing conditions apart from the two Cetopril formulations, the drug content of five other test formulations became substandard (Table 2). On average, the content of test drug formulations decreased $8.5 \pm 5.8 \%$. The largest decrease $(20.3 \%)$ was found for the methyldopa L\&A from Kenya, followed by methyldopa (Aldomet; $15.5 \%$ ) from Pakistan, and Captopril $25 \mathrm{mg}$ (Cetopril) and atenolol (Catenol) (both 10.4\%). The smallest decrease was found in both hydrochlorothiazide test formulations (2.8\% and $4.3 \%$ for HCTZ Cipla from India and HCTZ L\&A from Kenya, respectively) and was on average $3.6 \pm 1.1 \%$. The methyldopa formulations were by far the less stable formulations under accelerated testing conditions, with a loss of $17.9 \pm 4.4 \%$ of their content within 6-month storage at accelerated testing conditions. In addition, the methyldopa formulation from Kenya (Methyldopa L\&A) was macroscopically deteriorated (Figure 1). 
TABLE 2

Percentage of claimed drug content

\begin{tabular}{|c|c|c|c|c|}
\hline \multirow[b]{3}{*}{ Drug } & \multirow[b]{3}{*}{ Dose (mg) } & \multicolumn{3}{|c|}{ Percentage of claimed amount (the acceptance limit is $90-110 \%$ ) } \\
\hline & & \multirow{2}{*}{$\frac{t=0}{\text { At purchase }}$} & \multicolumn{2}{|c|}{$t=6$ months } \\
\hline & & & Long-term testing conditions & Accelerated testing conditions \\
\hline \multicolumn{5}{|l|}{ Atenolol } \\
\hline Tenormin* & 100 & 98.7 & 96.9 & 94.3 \\
\hline Betanorm & 100 & 96.0 & 95.1 & 90.4 \\
\hline Catenol & 100 & 97.1 & 93.8 & 86.7 \\
\hline \multicolumn{5}{|l|}{ Captopril } \\
\hline Capoten* & 25 & 98.8 & 98.9 & 97.3 \\
\hline Capoten* & 50 & 98.0 & 96.7 & 95.7 \\
\hline Captopril Denk & 25 & 96.4 & 95.7 & 94.7 \\
\hline Cetopril & 25 & 154.5 & 154.2 & 144.1 \\
\hline Cetopril & 50 & $\mathbf{5 3 . 0}$ & 50.9 & 44.5 \\
\hline \multicolumn{5}{|c|}{ Hydrochlorothiazide (HCTZ) } \\
\hline Esidrex* & 25 & 92.7 & 92.6 & 91.3 \\
\hline HCTZ L\&A & 50 & 94.3 & 91.3 & 90.0 \\
\hline HCTZ Cipla & 50 & 90.2 & 90.0 & 87.4 \\
\hline \multicolumn{5}{|l|}{ Methyldopa } \\
\hline Aldomet Belgium* & 250 & 97.3 & 96.3 & 94.9 \\
\hline Methyldopa L\&A & 250 & 90.6 & 89.1 & 70.3 \\
\hline Aldomet Pakistan & 250 & 92.2 & 90.0 & 76.7 \\
\hline \multicolumn{5}{|l|}{ Propranolol } \\
\hline Inderal* & 40 & 103.2 & 100.7 & 95.4 \\
\hline Cepanolol & 40 & 92.5 & 90.1 & 81.3 \\
\hline
\end{tabular}

The dissolution profiles of six test formulations $(60 \%)$ and none of the reference formulations became substandard after 6 months of accelerated testing conditions (Table 3). All hydrochlorothiazide test formulations passed the dissolution test. The largest decrease in dissolution from time of purchase occurred in the two atenolol test formulations $(18.7 \%$ and $18.1 \%$ for Catenol and Betanorm, respectively) and $17.3 \%$ for methyldopa (Aldomet) from Pakistan. The smallest decrease $(3.0 \%)$ occurred in hydrochlorothiazide Cipla from India. At
6 months under accelerated testing conditions, the similarity factor of dissolution profiles was substandard, showing loss of pharmaceutical equivalence compared with purchase in 7 of 10 test formulations and 1 (Inderal) of 6 reference formulations. Also, loss of pharmaceutical equivalence compared with the reference drug after 6 months under accelerated testing conditions was found in 9 of 10 test formulations ( $90 \%$; Table 4).

Compared with 6 months under long-term testing conditions, the dissolution profiles of all test drug formulations were

TABLe 3

Percentage of drug released by in vitro dissolution

\begin{tabular}{|c|c|c|c|c|c|c|}
\hline \multirow[b]{3}{*}{ Drug } & \multirow[b]{3}{*}{ Dose (mg) } & \multirow{3}{*}{$\begin{array}{l}\text { Dissolution duration } \\
\text { (minutes) }\end{array}$} & \multirow{3}{*}{$\begin{array}{l}\text { Recommended amount of } \\
\text { drug to be released }(\%)\end{array}$} & \multicolumn{3}{|c|}{ Percentage of amount of released drug after a recommended period* } \\
\hline & & & & \multirow{2}{*}{$\frac{t=0}{\text { At purchase }}$} & \multicolumn{2}{|c|}{$t=6$ months } \\
\hline & & & & & Long-term testing conditions & Accelerated testing conditions \\
\hline \multicolumn{7}{|l|}{ Atenolol } \\
\hline Tenormin $\dagger$ & 100 & 30 & $\geq 80$ & 99.8 & 94.9 & 93.8 \\
\hline Betanorm & 100 & & & 97.6 & 94.5 & 79.5 \\
\hline Catenol & 100 & & & 98.4 & 84.3 & 79.7 \\
\hline \multicolumn{7}{|l|}{ Captopril } \\
\hline Capoten $\dagger$ & 25 & 20 & $\geq 80$ & 96.6 & 96.4 & 94.0 \\
\hline Capoten $\dagger$ & 50 & & & 99.2 & 98.4 & 95.0 \\
\hline Captopril Denk & 25 & & & 98.8 & 98.4 & 90.7 \\
\hline Cetopril & 25 & & & 94.1 & 88.5 & 85.6 \\
\hline Cetopril & 50 & & & 82.4 & 81.4 & 79.4 \\
\hline \multicolumn{7}{|c|}{ Hydrochlorothiazide (HCTZ) } \\
\hline Esidrex $\dagger$ & 25 & 60 & $\geq 60$ & 98.5 & 97.7 & 97.4 \\
\hline HCTZ L\&A & 50 & & & 89.0 & 86.5 & 86.0 \\
\hline HCTZ Cipla & 50 & & & 93.3 & 93.3 & 84.8 \\
\hline \multicolumn{7}{|l|}{ Methyldopa } \\
\hline Aldomet Belgium $\dagger$ & 250 & 20 & $\geq 80$ & 97.9 & 96.8 & 96.3 \\
\hline Methyldopa L\&A & 250 & & & 88.5 & 84.3 & 78.8 \\
\hline Aldomet Pakistan & 250 & & & 96.5 & 95.4 & 79.2 \\
\hline \multicolumn{7}{|l|}{ Propranolol } \\
\hline Inderal $\dagger$ & 40 & 30 & $\geq 75$ & 89.0 & 89.0 & 86.7 \\
\hline Cepanolol & 40 & & & 84.4 & 82.7 & 73.2 \\
\hline
\end{tabular}

Substandard dissolution profiles are shown in bold

* Percent of the amount released has been calculated taking into account the real amount of drug per tablet at that storage time.

$\dagger$ Reference drug. 
TABLE 4

Similarity factors of dissolution profiles

\begin{tabular}{|c|c|c|c|c|c|c|}
\hline \multirow[b]{4}{*}{ Drug } & \multirow[b]{4}{*}{ Dose (mg) } & \multicolumn{5}{|c|}{ Values of similarity factor of dissolution profiles } \\
\hline & & \multicolumn{3}{|c|}{$\begin{array}{l}\text { Compared with the reference drug dissolution } \\
\text { profile at similar storage time }\end{array}$} & \multirow{2}{*}{\multicolumn{2}{|c|}{$\begin{array}{c}\text { Compared with the same drug formulation } \\
\text { dissolution profile at purchase }\end{array}$}} \\
\hline & & \multirow{2}{*}{$\begin{array}{c}t=0 \\
\text { At } \\
\text { purchase }\end{array}$} & \multicolumn{2}{|c|}{$t=6$ months } & & \\
\hline & & & $\begin{array}{l}\text { Long-term testing } \\
\text { conditions }\end{array}$ & $\begin{array}{l}\text { Accelerated testing } \\
\text { conditions }\end{array}$ & $\begin{array}{l}\text { Long-term testing } \\
\text { conditions }\end{array}$ & $\begin{array}{l}\text { Accelerated testing } \\
\text { conditions }\end{array}$ \\
\hline \multicolumn{7}{|l|}{ Atenolol } \\
\hline Tenormin* & 100 & Reference & Reference & Reference & 58 & 57.8 \\
\hline Betanorm & 100 & 50.4 & 38.2 & 32.1 & 52.5 & 38.3 \\
\hline Catenol & 100 & 55.7 & 31.8 & 28.2 & 46.9 & 43.1 \\
\hline \multicolumn{7}{|l|}{ Captopril } \\
\hline Capoten* & 25 & Reference & Reference & Reference & 75.2 & 54.3 \\
\hline Capoten* & 50 & Reference & Reference & Reference & 52.4 & 61.6 \\
\hline Captopril Denk & 25 & 60.9 & 50.2 & 63.7 & 57.9 & 56.1 \\
\hline Cetopril & 25 & 35.1 & 37.1 & 29.1 & 65.8 & 53.5 \\
\hline Cetopril & 50 & 39.1 & 34.2 & 30.2 & 51.7 & 61.1 \\
\hline \multicolumn{7}{|c|}{ Hydrochlorothiazide (HCTZ) } \\
\hline Esidrex* & 25 & Reference & Reference & Reference & 74.5 & 77.2 \\
\hline HCTZ L\&A & 50 & 49.6 & 36.3 & 44.2 & 71.9 & 46.6 \\
\hline HCTZ Cipla & 50 & 68.7 & 58.3 & 37.5 & 68.8 & 41.3 \\
\hline \multicolumn{7}{|l|}{ Methyldopa } \\
\hline Aldomet Belgium* & 250 & Reference & Reference & Reference & 67 & 56.4 \\
\hline Methyldopa L\&A & 250 & 60 & 46.7 & 34.2 & 55.9 & 60.1 \\
\hline Aldomet Pakistan & 250 & 52.5 & 50.6 & 33.3 & 81.8 & 41.3 \\
\hline \multicolumn{7}{|l|}{ Propranolol } \\
\hline Inderal* & 40 & Reference & Reference & Reference & 51.9 & 43.6 \\
\hline Cepanolol & 40 & 69.3 & 64.1 & 40.3 & 35.6 & 37.9 \\
\hline
\end{tabular}

Reference drug.

on average $7.5 \pm 6.0 \%$ lower after 6 months under accelerated testing conditions storage. The largest difference was found for methyldopa (Aldomet) from Pakistan (16.2\%), followed by methyldopa from Kenya (15.4\%) and atenolol (Betanorm; $15 \%)$. The smallest difference was recorded for hydrochlorothiazide L\&A from Kenya ( $0.5 \%)$.

\section{DISCUSSION}

This study showed poor quality of some antihypertensive drugs at purchase (2 of 10 formulations) and degradation of antihypertensive drugs under accelerated testing conditions. After 6 months of storage under accelerated testing conditions, 8 of 10 formulations became substandard for the combined criteria of drug content and dissolution test. The presence of substandard quality antihypertensive drugs is probably not limited to Rwandan pharmacies but is likely the situation in many other SSA countries. The authors are not aware of a similar or related study previously done on antihypertensive drugs in SSA, which shows how little the problem is addressed.
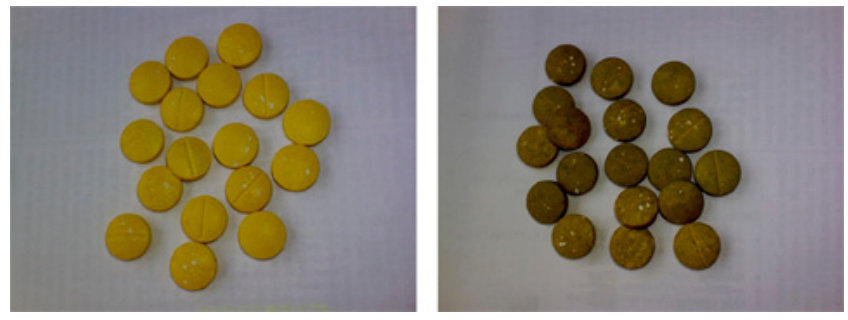

FIGURE 1. Macroscopic aspect of methyldopa L\&A at purchase time (left) and after 6-month storage at simulated tropical conditions (right). This figure appears in color at www.ajtmh.org.
Data about substandard drugs in SSA remain scattered and heterogeneous in various drug classes. The literature reports $4-100 \%$ of anti-infectious drugs substandard in content at the time of purchase in different SSA countries ${ }^{12}$ such as Sudan, ${ }^{7}$ Kenya, ${ }^{30}$ and Nigeria. ${ }^{9,31,32}$ In this study, the percentage of content substandard drugs at purchase was $20 \%$, whereas Risha and others ${ }^{13}$ and Kayumba and others ${ }^{10}$ reported in their series no formulation substandard in content at purchase. In this study, the drug content at purchase ranged from $44.5 \%$ to $144.1 \%$ of the claimed content. This was because of two substandard formulations most likely caused by a manufacturer error. The presence of substandard formulations caused by a manufacturer error has also been reported by other authors and ranged from $19 \%$ to $168 \%$ of the claimed content in antimalarial drugs in the Americas. ${ }^{12}$ Apart from manufacturer errors, the large variability in percentage of substandard drugs may also be linked to the variation in time drugs were exposed to tropical climate conditions, which was not known at the time of purchase. Indeed, after 6 months at accelerated testing conditions, the percentage of substandard antihypertensive drugs increased in this study from $20 \%$ to $80 \%$ and was higher than the $12 \%$ of substandard anti-infectious drugs from Tanzania and Rwanda. ${ }^{10}$

This study also showed that both drug content and drug dissolution can be altered under accelerated testing conditions and that drugs being within the quality limits of drug content may have a decreased bioavailability as shown by substandard dissolution profiles. The latter was the case for atenolol (Betanorm) in this study.

Currently, a struggle to increase the global pharmaceutical market is significantly being expanded in developing countries, ${ }^{2}$ especially in SSA. During importation of new pharmaceutical products, government and/or private pharmacies rely on the stability tests that are mandatory during formu- 
lation development. , $, 4,33^{2}$ This study shows that probably not all manufacturers comply with this requirement. This is in line with the idea that substandard drug cases are under-reported and are often confused with counterfeit drugs, causing limited understanding of the extent of the problem. ${ }^{19}$ This underlines the need for on-market drug quality monitoring.

In developing countries, governments often purchase drugs without adequate reference to quality standards. ${ }^{19}$ In some settings, non-governmental organizations (NGOs) working in developing countries issue drug tenders without applying minimum quality assurance procedures. ${ }^{19}$ Moreover, the capacity for technical evaluation or on-field drug quality monitoring is limited. ${ }^{2}$ The World Health Organisation (WHO) estimates that only a few countries have fully functional drug regulatory systems. ${ }^{19}$ Even if efforts are being made, in many SSA countries, relatively simple chromatographic or pharmacopeial methods for quality verification are not routinely available ${ }^{34}$ or used effectively. ${ }^{35}$ Although drug registration is normally a prerequisite for purchase in resource-limited countries, authorization to register a medicine is often granted based on a simple review of documents. Obviously, the quality is impossible to assure in the absence of proper controls that at minimum would include verification of information submitted for evaluation through site inspections, review of batch documentation, and random analysis of drugs supplied. In developing countries, a pharmacovigilance system is very often lacking. The setting up of a functioning pharmacovigilance system, which allows for the rapid communication of problems and recall of harmful drugs, is a costly and complicated process that has to compete with many other pressing health system priorities in resource-limited settings. ${ }^{19}$

The importance of substandard drugs may also be linked to low cost of those drugs, especially in the SSA settings, where the price of drugs is a major determinant of care accessibility and where drugs are paid out-of-pocket by patients.

This study has some limitations. A first limitation is the use of in vitro dissolution tests as a surrogate for in vivo bioavailability. In vitro dissolution is more rapid and much less expensive than an in vivo bioavailability study. However, whereas normal dissolution may suggest good bioavailability, ${ }^{22}$ a substandard dissolution profile does not automatically imply a low oral bioavailability. ${ }^{23}$ The latter should be confirmed with an in vivo bioavailability study. Another limitation may be linked to the unknown storage time and storage conditions of the drug samples before purchase that could have influenced the findings. However, because the quality of 8 of 10 formulations was sufficient at the time of purchase and most of them degraded during storage, this limitation is likely of lesser importance. In addition, non-active ingredients (excipients) or their degradation products have not been investigated in this study and may harm human health as toxic ingredients. ${ }^{19}$ Because the packaging material of the different formulations was unknown to the authors, the possible effect of this parameter on drug stability could not be assessed. The findings from this study suggested that some pharmaceutical manufacturers do not take special measures for drugs marketed in climate Zone IVA or IVB. Risha and others ${ }^{20}$ reported similar findings for different drug categories because several drug formulations imported into Tanzania were not optimized for stability in a tropical climate.

In this study, medicines were bought from official pharmacies where drugs are stored in the original package. Apart from official pharmacies, medicines are sold on SSA markets per tablet without the original package, thereby increasing the exposure to high humidity. It is likely that those drugs are more sensitive to quality degradation compared with the results found in this study.

Using drug content analysis and in vitro dissolution tests, 2 of 10 antihypertensive drug formulations were substandard at purchase. In addition, after 6 months of storage at accelerated testing (simulated tropical climate) conditions, 8 of 10 test drugs were substandard for the combined criteria of drug content and dissolution test, whereas none of the reference drugs became substandard. This suggests a deleterious effect of tropical climate on the antihypertensive drug in Rwanda and probably also in other SSA countries sharing the same tropical climate. In this study, the hydrochlorothiazide formulations were the most stable drug formulations. Because the use of drugs of substandard quality may alter treatment outcome, this study shows the need for on-market drug quality monitoring.

Received February 26, 2009. Accepted for publication July 14, 2009.

Acknowledgments: The authors acknowledge the help of Jan Kips in data verification. They extend their thanks to the investigators who helped in collecting drug samples in Rwanda, as well as to the team of the Laboratory of Pharmaceutical Technology at Faculty of Pharmaceutical science of Ghent University for their help during experiments.

Financial support: Marc Twagirumukiza has a PhD Fellowship sponsored by VLIR (Vlaamse Interuniversitaire Raad: Flemish Interuniversity Council) in Belgium through Ghent University and the National University of Rwanda. All standards and reagents were kindly supplied by the laboratory of pharmaceutical technology at Ghent University.

Disclosure: The authors declare that there is no interest conflict to disclose.

Authors' addresses:Marc Twagirumukiza and LucVan Bortel,Heymans Institute of Pharmacology, Ghent University, De Pintelaan 185, Block B 1 $1^{\text {st }}$ Floor, 9000 Ghent, Belgium, E-mails: Marc.Twagirumukiza@ UGent.be and Luc.VanBortel@UGent.be. An Cosijns, Eveline Pringels, Jean Paul Remon, and Chris Vervaet, Laboratory of Pharmaceutical Technology, Ghent University, Harelbekestraat 72, 9000 Ghent, Belgium, E-mail: Chris.Vervaet@UGent.be.

\section{REFERENCES}

1. Wan Po AL, 2001. Too much, too little, or none at all: dealing with substandard and fake drugs. Lancet 357: 1904.

2. Bott RF, Oliveira WP, 2007. Storage conditions for stability testing of pharmaceuticals in hot and humid regions. Drug Dev Ind Pharm 33: 393-401.

3. Kommanaboyina B, Rhodes CT, 1999. Trends in stability testing, with emphasis on stability during distribution and storage. Drug Dev Ind Pharm 25: 857-868.

4. Ballereau F, Prazuck T, Schrive I, Lafleuriel MT, Rozec D, Fisch A, Lafaix C, 1997. Stability of essential drugs in the field: results of a study conducted over a two-year period in Burkina Faso. Am J Trop Med Hyg 57: 31-36.

5. Videau JY, Fundafunda B, 2000. Generic drugs: the hidden issues of quality and cost. WHO Drug Inform 14: 77-81.

6. Behrens RH, Awad AI, Taylor RB, 2002. Substandard and counterfeit drugs in developing countries. Trop Doct 32: 1-2.

7. Hogerzeil HV, de Goeje MJ, bu-Reid IO, 1991. Stability of essential drugs in Sudan. Lancet 338: 754-755.

8. Roy J, 1994. The menace of substandard drugs. World Health Forum 15: 406-407.

9. Taylor RB, Shakoor O, Behrens RH, Everard M, Low AS, Wangboonskul J, Reid RG, Kolawole JA, 2001. Pharmacopoeial quality of drugs supplied by Nigerian pharmacies. Lancet 357 : 1933-1936. 
10. Kayumba PC, Risha PG, Shewiyo D, Msami A, Masuki G, Ameye D, Vergote G, Ntawukuliryayo JD, Remon JP, Vervaet C, 2004. The quality of essential antimicrobial and antimalarial drugs marketed in Rwanda and Tanzania: influence of tropical storage conditions on in vitro dissolution. J Clin Pharm Ther 29: 331-338.

11. Petralanda I, 1995. Quality of antimalarial drugs and resistance to Plasmodium vivax in Amazonian region. Lancet 345: 1433.

12. Reidenberg MM, Conner BA, 2001. Counterfeit and substandard drugs. Clin Pharmacol Ther 69: 189-193.

13. Risha PG, Shewiyo D, Msami A, Masuki G, Vergote G, Vervaet $\mathrm{C}, \mathrm{Remon} \mathrm{JP}, 2002$. In vitro evaluation of the quality of essential drugs on the Tanzanian market. Trop Med Int Health 7: 701-707.

14. Unwin N, 2001. Non-communicable disease and priorities for health policy in sub-Saharan Africa. Health Policy Plan 16: 351-352.

15. Opie LH, Seedat YK, 2005. Hypertension in sub-Saharan African populations. Circulation 112: 3562-3568.

16. Murray CJ, Lopez AD, 1997. Alternative projections of mortality and disability by cause 1990-2020: Global Burden of Disease Study. Lancet 349: 1498-1504.

17. van der Sande MA, 2003. Cardiovascular disease in sub-Saharan Africa: a disaster waiting to happen. Neth J Med 61: 32-36.

18. Kearney PM, Whelton M, Reynolds K, Muntner P, Whelton PK, He J, 2005. Global burden of hypertension: analysis of worldwide data. Lancet 365: 217-223.

19. Caudron JM, Ford N, Henkens M, Mace C, Kiddle-Monroe R, Pinel J, 2008. Substandard medicines in resource-poor settings: a problem that can no longer be ignored. Trop Med Int Health 13: 1062-1072.

20. Risha PG, Vervaet C, Vergote G, Van Bortel L, Remon JP, 2003. Drug formulations intended for the global market should be tested for stability under tropical climatic conditions. Eur J Clin Pharmacol 59: 135-141.

21. World Health Organization, 2006. Access to medicines: production and export of generic medicines under the TRIPS Agreement. WHO Drug Information 20: 22-25.

22. Amidon GL, Lennernas H, Shah VP, Crison JR, 1995. A theoretical basis for a biopharmaceutic drug classification: the cor- relation of in vitro drug product dissolution and in vivo bioavailability. Pharm Res 12: 413-420.

23. Uppoor VR, 2001. Regulatory perspectives on in vitro (dissolution)/in vivo (bioavailability) correlations. J Control Release 72: 127-132.

24. International Conference on Harmonization (ICH). ICH Q1A(R2): Stability testing of new drug substances and products [Current step 4 version; dated 6 February 2003]. ICH Harmonised Tripartite Guideline. Available at: http://www.ich.org/LOB/media/ MEDIA419.pdf. Accessed December 2008.

25. Matthews BR, 1999. Regulatory aspects of stability testing in Europe. Drug Dev Ind Pharm 25: 831-856.

26. Unites States Pharmacopeial Convention, 2006. National Formulary (USP 29-NF 24). Rockville, MD: United States Pharmacopeia.

27. Moore JW, Flanner HH, 1996. Mathematical comparison of dissolution profiles. Pharm Technol 20: 64-74.

28. Shah VP, Tsong Y, Sathe P, Liu JP, 1998. In vitro dissolution profile comparison: Statistics and analysis of the similarity factor, f2. Pharm Res 15: 889-896.

29. Food and Drug Administration (FDA) and Centre for Drug Evaluation and Research, 1997. FDA Guidance for Industry: Dissolution Testing for Immediate Release Solid Oral Dosage Form. Rockville, MD: US Department of Health and Human Services.

30. Kibwage IO, Ogeto JO, Maitai CK, Rutere G, Thuranira J, Ochieng' A, 1992. Drug quality control work in Daru: observations during 1983-1986. East Afr Med J 69: 577-580.

31. Raufu A, 2002. Influx of fake drugs to Nigeria worries health experts. BMJ 324: 698.

32. Raufu A, 2003. India agrees to help Nigeria tackle the import of fake drugs. BMJ 326: 1234.

33. Zahn M, Kallberg PW, Slappendel GM, Smeenge HM, 2006. A risk-based approach to establish stability testing conditions for tropical countries. J Pharm Sci 95: 946-965.

34. Newton PN, Green MD, Fernandez FM, Day NP, White NJ, 2006. Counterfeit anti-infective drugs. Lancet Infect Dis 6: 602-613.

35. Risha P, Msuya Z, Ndomondo-Sigonda M, Layloff T, 2006. Proficiency testing as a tool to assess the performance of visual TLC quantitation estimates. J AOAC Int 89: 1300-1304. 